\title{
Impact of surface grafting density of PEG macromolecules on dually fluorescent silica nanoparticles used for the in vivo imaging of subcutaneous tumors.
}

\author{
Laurent Adumeau a, Coralie Genevois b, Lydia Roudier a, Christophe Schatz c, Franck \\ Couillaud ${ }^{\mathrm{b},}$, Stéphane Mornet ${ }^{\mathrm{a}, * *}$ \\ ${ }^{a}$ CNRS, Univ. Bordeaux, ICMCB, UPR 9048, F-33600 Pessac, France. \\ b Univ. Bordeaux, EA 7435 IMOTION - Imagerie moléculaire et thérapies innovantes en oncologie, 33706 \\ Bordeaux, France. \\ c CNRS, Univ. Bordeaux, LCPO, UMR 5629, F-33600, Pessac, France
}

* Correspondance to: F. Couillaud, EA 7435 IMOTION, case 127, 146 rue Léo Saignat, 33706 Bordeaux, France.

** Correspondance to: S. Mornet, Bordeaux Institute of Condensed Matter Chemistry, 87 avenue du Dr. A. Schweitzer, Pessac F-33600, France.

Email addresses: franck.couillaud@u-bordeaux.fr (F. Couillaud), stephane.mornet@icmcb.cnrs.fr (S. Mornet).

Keywords: Nanoparticle, PEGylation, Tumor, EPR effect, Fluorescence imaging, in vivo

\begin{abstract}
Abbreviations: NPs, nanoparticles; EPR, enhanced permeation and retention effect; i.v., intravenous, RES, reticuloendothelial system; PEG, polyethylene glycol; FRI, fluorescence reflectance imaging; NIR, near infra-red ; TEOS, Tetraethyl orthosilicate; MPS, (3-mercaptopropyl)triethoxysilane; DL650, Dylight ${ }^{\mathrm{TM}} 650$; DL800, Dylight ${ }^{\mathrm{TM}} 800 ; \quad$ EDPS, N-[3-(trimethoxysilyl)propyl]ethylenediamine; DCM, dichloromethane; TFA, trifluoroacetic acid; DCC, dicyclohexylcarbodiimide; DMSO, dimethylsulfoxide; TEM, transmission electron microscopy; DLS, dynamic light scattering; DRIFT, Diffuse reflectance infrared Fourier transform; TGA, thermogravimetric analysis; BLI, bioluminescence imaging.
\end{abstract}

\section{Abstract}

Background: In the context of systematically administered nanomedicines, the physicochemistry of NP surfaces must be controlled as a prerequisite to improve blood circulation time, and passive and active targeting. In particular, there is a real need to develop NP stealth and labelling for both in vivo and microscopic fluorescence imaging in a mice model.

Methods: We have synthesized NIR/red dually fluorescent silica nanoparticles of $19 \mathrm{~nm}$ covalently covered by a PEG layer of different grafting density in the brush conformational regime by using a reductive amination reaction. These particles were characterized by TEM, DRIFT, DLS, TGA, $\zeta$ potential measurements, UV-vis and fluorescence spectroscopy. Prostate tumors were generated in mice by subcutaneous injection of RM1-CMVFluc cells. Tumor growth was monitored by BLI after a D-luciferin injection. Four samples of PEGylated fluorescent NPs were individually intravenously injected into 6 mice $(N=6$, total 24 mice). Nanoparticle distribution was investigated using in vivo fluorescence reflectance imaging (FRI) over $48 \mathrm{~h}$ and microscopy imaging was employed to localize the NPs within tumors in vitro.

Results: Fluorescent NP accumulation, due to the enhanced permeability and retention (EPR) effect, increases gradually as a function of increased PEG surface grafting density with a huge difference observed for the highest density grafting. For the highest grafting density, a blood circulation time of up to $24 \mathrm{~h}$ was observed with a strong reduction in uptake by the liver. In vivo experimental results suggest that the biodistribution of NPs is very sensitive to slight variations in surface grafting density when the NPs present a high curvature radius.

Conclusion: This study underlines the need to compensate a high curvature radius with a PEG-saturated NP surface to improve blood circulation and accumulation within tumors through the EPR effect. Dually fluorescent NPs PEGylated to saturation display physical properties useful for assessing the susceptibility of tumors to the EPR effect.

General Significance: Control of the physicochemical features of nanoparticle surfaces to improve blood circulation times and monitoring of the EPR effect. 


\section{Introduction}

Determining the distribution of nanocarriers within the body upon systemic administration is one of the top priorities of nanomedicine [1]. In pursuit of this aim, there is a real need to develop labeled nanoparticles (NPs) to visualize the biodistribution in real time through imaging methods. Moreover, we must better understand the critical physicochemical parameters involved in the enhanced permeation and retention effect (EPR) of NPs $[2,3]$. Control over the physicochemical properties of NPs can determine the overall blood circulation kinetics [4], however, it is still hard to predict which type of NP can best estimate the susceptibility of the EPR effect in terms of the extravasation processes and intratumoral diffusion. In addition, NPs as exogenous materials are liable to be eliminated by the immune defense system, which represents one of the major barriers for systematically administered nanomedicines. When NPs are administered, many plasma proteins called opsonins adsorb to the NPs surface, which are recognized by the scavenger receptor of the macrophage cell of the reticuloendothelial system (RES) [5]. An accurate control of these physicochemical features would allow us to better negotiate uptake and retention by the RES $[6,7]$.

A way to prolong circulation of engineered nanoparticles is to develop anti-fouling strategies to reduce the effect of opsonization with plasma proteins. The gold standard to reduce non-specific protein adsorption and cellular uptake is to create a dense layer of polyethylene glycol (PEG) molecules on the nanoparticle surface (PEGylation). Many reviews have treated the topic concerning the interactions and circulation of PEGylated NPs in the blood, which depend on the influence of several key factors, including PEG molecular weight (MW), NP size, and PEG surface density [8-12]. Among these factors, the PEG surface grafting density on NPs is directly involved in the mechanism shielding against opsonins adsorption. It has been demonstrated that at a similar PEG grafting density, larger particles exhibit increased macrophage uptake compared to smaller NPs [13]. From these studies it also appears that to achieve stealth properties, there is a certain threshold of PEG surface density required far beyond the mushroom/brush transition [14]. The use of small NPs requires a higher PEG density to compensate for the spreading of flexible chains due to increased surface curvature. In this context, it seemed appropriate to address an in vivo study to highlight the impact on the EPR effect of slight variations in terms of PEG surface grafting density in the brush regime on highly curved NPs.

In the present study we synthesized fluorescent silica nanoparticles of $19 \mathrm{~nm}$ by incorporating near infra-red (NIR) and red fluorescent dyes to track their biodistribution in vivo over time by fluorescence reflectance imaging (FRI) and to check their localization in tumors by microscopic imaging. Four different levels of PEGylation grafting in the brush regime were produced by the use of a well-controlled surface chemistry. These PEGylated fluorescent NPs were injected intravenously in mice bearing subcutaneous tumors ( $N=6$, total 24 mice) in order to compare their accumulation in the 
liver and tumors through the EPR effect. After accurate quantification of PEG grafting density values by TGA analysis, the results are discussed in the light of recent reports [12-14].

\section{Materials and Methods}

\subsection{Chemicals}

Tetraethyl orthosilicate (TEOS, 99.999\%), (3-mercaptopropyl)triethoxysilane (MPS, 80\% technical grade), N-[3-(trimethoxysilyl)propyl]ethylenediamine (EDPS, 97\%), ammonium hydroxide solution (30\%, ACS reagent), absolute ethanol (EtOH), glycerol (BioXtra, $\geq 99 \%)$, dichloromethane (DCM, anhydrous, $\geq 99.8 \%$ ), trifluoroacetic acid (TFA, 99\% reagent grade), pyridine (anhydrous, 99.8\%), N,N'dicyclohexylcarbodiimide (DCC, $\geq 99 \%$ puriss.), petroleum ether (puriss., high boiling, bp $60-80{ }^{\circ} \mathrm{C}$ ), isopropanol ( $\geq 99.7 \%$ ), poly(ethylene glycol) methyl ether (mPEG5k, $\mathrm{Mn} 5000 \mathrm{~g} / \mathrm{mol}$ ), sodium borohydride $\left(\mathrm{NaBH}_{4}, 99.99 \%\right)$, methanol ( $\mathrm{MeOH}$, anhydrous, 99.8\%) and triethylamine $\left(\mathrm{Et}_{3} \mathrm{~N}, \geq 99.5 \%\right)$ were purchased from Sigma-Aldrich (Saint-Quentin Fallavier, France). Hydrochloric acid (37\%, Normapur) was purchased from VWR (Fontenay-sous-Bois, France). Dylight ${ }^{\mathrm{TM}} 650$-maleimide (DL650mal, $\lambda_{\mathrm{Ex}} / \lambda_{\mathrm{Em}} 654 / 672 \mathrm{~nm}$ ), Dylight ${ }^{\mathrm{TM}} 800$-maleimide (DL800-mal, $\lambda_{\mathrm{Ex}} / \lambda_{\mathrm{Em}} 770 / 794 \mathrm{~nm}$ ) and anhydrous dimethylsulfoxide (DMSO) were purchased from ThermoFisher Scientific, Illkirch, France). Sterile ultrapure water (18 M $\Omega$ ) was produced using a SG-Labostar (7 TWF-UV) system from Odemi (Grisy, France). All materials were used as received, unless otherwise indicated.

\subsection{Synthesis of dually fluorescent silica nanoparticles (DF-SiO ${ }_{2} \mathrm{NPs}$ )}

DL650-mal $\left(9.2 \cdot 10^{-7} \mathrm{~mol}, 1\right.$ eq., Thermo Scientific $\left.{ }^{\top \mathrm{M}}\right)$ was dissolved in $100 \mu \mathrm{L}$ of anhydrous DMSO. This fresh solution was added to $250 \mu \mathrm{L}$ of absolute EtOH containing $3.68 \cdot 10^{-6} \mathrm{~mol}$ of 3mercaptopropyl)triethoxysilane (MPS, 4 eq.). The mixture was stirred for $2 \mathrm{~h}$ at room temperature in the dark. DL800-mal (9.3·10-7 mol, 1 eq.) was dissolved in $800 \mu \mathrm{L}$ of anhydrous DMSO. This solution was added to a solution composed of $250 \mu \mathrm{L}$ of absolute $\mathrm{EtOH}$ and $3.72 \cdot 10^{-7} \mathrm{~mol}$ of MPS (4 eq.). The mixture was stirred for $2 \mathrm{~h}$ at room temperature in the dark. Then, a solution composed of $37 \mathrm{~mL}$ of absolute EtOH, $762.5 \mu \mathrm{L}$ of TEOS and the solutions of freshly prepared fluorescent silanes was rapidly added under continuous stirring to a solution composed of $99 \mathrm{~mL}$ of absolute $\mathrm{EtOH}, 3.7 \mathrm{~mL}$ of ammonia $(30 \% \mathrm{w} / \mathrm{w})$ and $0.4 \mathrm{~mL}$ of deionized water. The mixture was stirred for $12 \mathrm{~h}$ at room temperature in the dark. An additional thin silica layer was grown by adding $41 \mathrm{~mL}$ of deionized water and $550 \mu \mathrm{L}$ of TEOS with a flow rate of $0.5 \mathrm{~mL} / \mathrm{h}$ under gentle stirring. Four hours after the end of TEOS addition, ammonia was removed by evaporation under reduced pressure at $50{ }^{\circ} \mathrm{C}$. The obtained nanoparticles are named DF-SiO ${ }_{2} \mathrm{NPs}$. 


\subsection{Surface modification of DF-SiO ${ }_{2}-N P s$ with an amino-silane coupling agent (DF-SiO $\left.{ }_{2} N P s-E D P S\right)$}

The surface modification of colloidal silica was carried out according to reported methods [15-16]. Briefly, $1.7 \mathrm{~mL}$ of EDPS was added under vigorous stirring to disperse DF-SiO${ }_{2} \mathrm{NPs}$ representing $470 \mathrm{~m}^{2}$ in developed surface area. After the overnight reaction under gentle stirring, a volume of $28 \mathrm{~mL}$ of glycerol was added and $\mathrm{EtOH}$ and water were removed under reduced pressure. Then the mixture was heated to $100^{\circ} \mathrm{C}$ under vacuum for $1 \mathrm{~h}$. Finally, excess EDPS and glycerol were removed through several washes (7 times with a dilution factor of about 15) with EtOH using tangential flow filtration using $300 \mathrm{kDa}$ cutoff ultra-filtration filters (Merck Millipore). Then a few droplets (about $50 \mu \mathrm{L}$ ) of glacial acetic acid were added in order to favor the colloidal stabilization by protonation of amine groups. The washing was prolonged three times with anhydrous $\mathrm{MeOH}$. The modified NPs named DF$\mathrm{SiO}_{2} \mathrm{NPs}$-EDPS were stored in this form at room temperature in the dark $\left(\mathrm{CsiO}_{2}=58.9 \mathrm{~g} / \mathrm{L}\right.$, estimated by dry weight).

\subsection{Preparation of methoxypoly(ethylene glycol) acetaldehyde derivatives (mPEG5K-ald)}

Aldehyde activated methoxypoly(ethylene glycol) (mPEG5K-ald) was produced by a metal-free Pfitzner-Moffatt oxidation according to modified procedures [17-19]. mPEG5K $\left(\mathrm{M}_{\mathrm{n}}=5000 \mathrm{~g} / \mathrm{mol}\right.$, Fluka) (50 g, $10 \mathrm{mmol}, 1$ eq.) was dissolved in $65 \mathrm{~mL}$ of anhydrous DMSO. Traces of water were firstly removed by evaporation of $20 \mathrm{~mL}$ of DMSO under reduced pressure at $80^{\circ} \mathrm{C}$. After cooling to room temperature, $50 \mathrm{~mL}$ of anhydrous DCM were added. Pyridine $(1.68 \mathrm{~mL}, 20 \mathrm{mmol}, 2$ eq.) and TFA ( $770 \mu \mathrm{L}, 10 \mathrm{mmol}, 1$ eq.) were then added under stirring at $4{ }^{\circ} \mathrm{C}$ in an ice bath. After $30 \mathrm{~min}$ of stirring, $\operatorname{DCC}(12,4 \mathrm{~g}, 60 \mathrm{mmol}, 6 \mathrm{eq}$.) was added and the mixture was kept in the ice bath for $20 \mathrm{~h}$ while stirring. The precipitate resulting from the dicyclohexylurea by-product was then removed by filtration at $4{ }^{\circ} \mathrm{C}$. Thereafter, a cold solution of petroleum ether/propan-2-ol (4:1 vol \%, $600 \mathrm{~mL})$ was added in order to precipitate the mPEG5K-ald at $-4{ }^{\circ} \mathrm{C}$. The solid polymer was dissolved in $100 \mathrm{~mL}$ of dichloromethane, recrystallized using $500 \mathrm{~mL}$ of diethyl ether, recovered by filtration and dried under vacuum (weighing $43.5 \mathrm{~g}$, yield $87 \%)$. The powder was stored at $-20^{\circ} \mathrm{C}$.

\subsection{Grafting of mPEG5K-ald on the surface of DF-SiO ${ }_{2} \mathrm{NPs}$-EDPS}

Four batches were generated with various amount of mPEG5K-ald: Sample A corresponds to about a 22-fold excess of PEG-5k-ald macromolecules compared to the total primary amine functions exposed on the NP surface, 2-fold excess for Sample B, stoichiometric conditions for Sample C and a 0.2 equivalent of PEG macromolecules for Sample D. Aliquots of $2.9 \mathrm{~g}, 0.29 \mathrm{~g}, 0.145 \mathrm{~g}$ and $0.029 \mathrm{~g}$ of mPEG5K-ald were diluted in $7.25 \mathrm{~mL}$ of anhydrous $\mathrm{MeOH}$. Then, a volume of $849.2 \mu \mathrm{L}$ of DF-SiO ${ }_{2} \mathrm{NPs}-$ EDPS dispersion (corresponding to $50 \mathrm{mg}$ for a total surface area of $\sim 7.89 \mathrm{~m}^{2}$ ) was added dropwise 
while vigorously stirring each sample. After $5 \mathrm{~min}$, a volume of $33.3 \mu \mathrm{L}$ of $\mathrm{Et}_{3} \mathrm{~N}$ was added. The mixtures were protected from light and left to react for $4 \mathrm{~h}$ under reflux at $70^{\circ} \mathrm{C}$. Then a mass of $56 \mathrm{mg}$ of $\mathrm{NaBH}_{4}$ was added to each sample while stirring at room temperature and a volume of $1.5 \mathrm{~mL}$ of $1 \mathrm{M} \mathrm{HCl}$ was added 10 min later. The resulting samples of PEGylated NPs, were purified with ultrapure water by tangential flow filtration using $300 \mathrm{kDa}$ cutoff filters. The washing step was achieved so as to obtain for each sample an identical concentration of residual free PEG chains of the order of $10^{-7} \mathrm{~g} / \mathrm{L}$. For instance, in a $10 \mathrm{~mL}$ filtration cell, the volume of sample A was reduced to $500 \mu \mathrm{L}$ that gives a dilution factor of 20. This procedure was applied 6 times to reach a dilution factor of $6.410^{7}$. Each PEGylated NP sample was suspended in a final volume of $4 \mathrm{~mL}$ to obtain stock solutions with a concentration of about $12.5 \mathrm{~g} / \mathrm{L}$ in $\mathrm{SiO}_{2}$. All dispersions were protected from light and stored at room temperature.

\subsection{Physico-chemical properties of PEGylated $\mathrm{DF}-\mathrm{SiO}_{2} \mathrm{NPs}$}

The size of nanoparticles was assessed by transmission electron microscopy (TEM). A volume of $5 \mu \mathrm{L}$ of dispersed NPs was deposited on a carbon-film covered copper grid and allowed to adsorb for $1 \mathrm{~min}$. The excess liquid was then removed using Whatman filter paper. TEM micrographs were performed with a Philips CM120 microscope operating at $120 \mathrm{kV}$ and captured with an Ultra scan USC1000 2k $\times 2 k$ camera. NP size assessment was performed with Digital Micrograph software from Gatan.

The molar masses of mPEG5K and mPEG5K-ald were characterized by size-exclusion chromatography with a multiangle light scattering detection (WYATT, Dawn Heleos II) equipped with a JascoPU-980 pump and a differential refractive index detector (WYATT, Optilab rEX) in order to determine the average molecular weights $(\mathrm{Mw})$ and dispersity (Mw/Mn). The ASTRA software (WYATT) controls the apparatus. The PEG molecules were analyzed in 0.01M Na $\mathrm{HPO}_{4} / 0.2 \mathrm{M} \mathrm{NaNO}_{3}, \mathrm{pH} 9$ using two columns from Shodex (OHpak SB-804 HQ) and a guard column. The flow rate was set to $0.6 \mathrm{~mL} / \mathrm{min}$ and the injected volume was $100 \mu \mathrm{L}$. The $\mathrm{dn} / \mathrm{dc}$ values were determined for each polymer with a differential refractive index detector (WYATT, Optilab rEX) in same buffer conditions as for the chromatographic elution.

${ }^{1} \mathrm{H}$-NMR spectrum of mPEG5K-ald was performed in $\mathrm{CDCl}_{3}$ with a Bruker NMR spectroscope working at 9.4 Tesla (400 MHz) (Spectrum shown in supplementary material document).

Hydrodynamic sizes and $\zeta$ potential were analyzed using a Zetasizer NanozS from Malvern instruments (Worcestershire, UK) at various $\mathrm{pH}$ values, before and after being diluted by a factor of 2 with PBS buffer at $2 \mathrm{mg}\left(\mathrm{SiO}_{2}\right) \cdot \mathrm{L}^{-1}$. For dynamic light scattering (DLS) measurements, NP dispersions are systematically filtered with membrane disks with a $0.22 \mu \mathrm{m}$ pore size (Durapore, Millipore).

Diffuse reflectance infrared Fourier transform (DRIFT) spectroscopy was performed with a Bruker IFS Equinox $55 \mathrm{FTIR}$ spectrometer (signal averaging 32 scans at a resolution of $4 \mathrm{~cm}^{-1}$ ) equipped by a 
selector Graseby Specac diffuse reflection cell (Eurolabo, France). A volume of the NP dispersion was dried at $80^{\circ} \mathrm{C}$ under vacuum to obtain the sample in powder form. Then, samples were prepared by spreading crushed powders (3 wt \%) in anhydrous (spectroscopy grade) $\mathrm{KBr}$ on a conical support.

For thermogravimetric analysis (TGA), $10 \mathrm{mg}$ of nanoparticles, previously dried at $90{ }^{\circ} \mathrm{C}$ under a primary vacuum for $12 \mathrm{~h}$, were placed in a platinum crucible, which was positioned on a Tag2400 thermobalance from Setaram (Caluire-et-Cuire, France). TGA measurements were consisted of a first temperature cycle from $25^{\circ} \mathrm{C}$ to $650^{\circ} \mathrm{C}$ by increasing the heat by $2{ }^{\circ} \mathrm{C} / \mathrm{min}$ under an $\mathrm{Ar}$ flux in order to favor the thermal decomposition of macromolecules in a short range of time. A second cycle (25$650{ }^{\circ} \mathrm{C}, 10{ }^{\circ} \mathrm{C} / \mathrm{min}$ ) was applied under an $\mathrm{O}_{2}$ flux, heating up to $1000^{\circ} \mathrm{C}$ to completely combust the organic matter. According to differentiated TGA diagrams, the surface grafting densities, $\sigma$, are assessed by subtraction of mass losses between $300{ }^{\circ} \mathrm{C}$ and $690{ }^{\circ} \mathrm{C}$ so as not to overestimate these values due to the remaining physisorbed water molecules at lower temperatures. Moreover, contributions of organic moieties of an aminated polysiloxane film, chemisorbed water and remaining ethoxy groups were subtracted from the total mass loss measured (see also SI document for calculations details).

The absorption spectra were recorded in the range of 400-900 nm with an UV-3600 Shimadzu UVVis-NIR spectrophotometer using $1 \mathrm{~cm}$ optical path length plastic cells.

Fluorescence measurements were carried out using a Fluorolog Fl3, Triax 320 luminescence spectrometer (Horiba Jobin Yvon, Les Ulis, France).

\subsection{Cancer cell line generation and culture}

Murine prostate cancer cell line RM1 was obtained from Dr T.C. Thompson (Baylor College of Medicine, Houston, TX, USA) and Dr M. P. Monteiro (University of Porto, Portugal). The RM1 cell line was maintained in Dulbecco's modified Eagle's medium (Invitrogen, Carlsbad, CA, USA) supplemented with $10 \%$ fetal bovine serum (Invitrogen) and 1\% antimycotic-antibiotic mix (PSA, Invitrogen). The RM1 cell line was stably transfected with pcDNA6.2-CMV-Fluc [20] vector using Lipofectamine ${ }^{\circledR} 2000$ Reagent (Invitrogen) and blasticidin ( $10 \mu \mathrm{g} / \mathrm{mL}$, Euromedex, Souffelweyersheim, France) was used for cell line selection. Cell lines were maintained in a humidified $5 \% \mathrm{CO}_{2}$ incubator at $37^{\circ} \mathrm{C}$.

\subsection{Animals handling and tumor generation}

Animal manipulations were performed in agreement with French and European directives on the care and use of animals and have been approved by the local ethical committee (CEEA 50) under agreement A50120196. B6 Albino (B6N-Tyr ${ }^{c-B r d} / \mathrm{BrdCrCrl}$ ) mice (6- to 8-weeks-old) were reared at the University of Bordeaux animal facilities. Animals were maintained in standard conditions under a 12hour light/dark cycle with water and food provided ad libitum. Animals were anesthetized with $2 \%$ 
isoflurane (Belamont, Nicholas Piramal Ltd, London, UK) in air. For tumor generation, cells $\left(2.10^{6}\right.$ cells $/ 100 \mu \mathrm{L}$ ) were injected subcutaneously on the right leg. Prior to the imaging session, the regions of the mice to be imaged were shaved with clippers and a depilatory cream. Each dispersion was filtered with $0.22 \mu \mathrm{m}$ pore size membrane disks and equilibrated by dilution two times with an equal volume of PBS $2 \mathrm{X}$ before injection via the tail vein $\left(160 \mu \mathrm{L}, 6.25 \mathrm{~g}\left(\mathrm{SiO}_{2}\right) / \mathrm{L}\right)$. One week $(7$ days $)$ after injection of RM1 cells, the four samples A, B, C and D were individually intravenously administered into 6 mice ( $N=6$, total 24 mice).

\subsection{Bioluminescence imaging (BLI)}

BLI was performed at Vivoptic (UMS 3767 - Univ. Bordeaux) using Lumina LT (Perkin Elmer Inc., Boston, MA, USA). Mice received an intra-peritoneal injection of D-luciferin (Promega, Madison, WI, USA; $2.9 \mathrm{mg}$ in $100 \mu \mathrm{LPBS}$ ), were sedated $5 \mathrm{~min}$ later and images were taken at $8 \mathrm{~min}$. Bioluminescence images (1 min, $4 \times 4$ binning) and photographs (100 ms) were acquired successively. The bioluminescence signal was analyzed using Living Image software.

\subsection{Fluorescence reflectance imaging (FRI)}

FRI was performed using the Lumina LT apparatus (Perkin Elmer). Excitation was performed at $745 \mathrm{~nm}$ and fluorescence emission was detected with the $810-875 \mathrm{~nm}$ filter. A region of interest was placed on the tumor to allow for the quantification of fluorescence signal $\left(\mathrm{ph} . \mathrm{s}^{-1}\right)$ using Living Image software.

\subsection{Histochemistry and microscopic imaging}

Tumors were fixed overnight at $4{ }^{\circ} \mathrm{C}$ with $4 \%$ paraformaldehyde, frozen and stored at $-80{ }^{\circ} \mathrm{C}$. Slices $(10 \mu \mathrm{M})$ were then obtained and permeabilized with PBS-Triton $0.5 \%$. Cryosections were mounted in ProLong ${ }^{\circledR}$ Gold antifade reagent with DAPI (Invitrogen). Microscopic images were acquired with the Leica DM 5000 microscope (Leica Microsystems, Wetzlar, Germany). DAPI detection was performed using an excitation filter of 340-380 nm and an emission filter of 450-490 nm. Dylight 650 fluorescence detection was performed using an excitation filter of 590-650 nm and an emission filter of $665-735 \mathrm{~nm}$

\section{Results}

\subsection{Synthesis of aminated silica nanoparticles dually labelled with fluorescent dyes}

Fluorescent dye doped silica nanoparticles were produced according to a slightly modified sol-gel procedures [21-23] in order to obtain NPs of about $15 \mathrm{~nm}$ diameter (Fig. 1a,b). Dually fluorescent NPs 
(DF-SiO 2 NPs) obtained by incorporation of two dyes, DL 650 and DL 800, were produced to enable in vivo optical imaging and microscopic observations of the same sample at different scales (from cellular to small animal imaging). An additional silica layer $2 \pm 0.5 \mathrm{~nm}$ in thickness was grown around the fluorescent silica NPs (Fig. 1b,c) in order to protect of the degradation the fluorescent dyes towards further surface chemical treatments. The chemical surface modification of $\mathrm{DF}-\mathrm{SiO}_{2} \mathrm{NPs}$ through silanization with EDPS was performed according to an optimized method previously described [15-16]. This surface modification procedure gives a surface grafting density of $3.4 \mu \mathrm{mol} / \mathrm{m}^{2}$ (i.e. $2 \mathrm{RNH} / \mathrm{nm}^{2}$ ) with an isoelectric point of 9.5 close to the pKa value of aminoalkyl groups (DRIFT spectra, Zeta potential measurements and TGA are shown in supplementary material document, Figs. S1,2,4). This value of IEP has been achieved due to the thermal treatment applied in a wetting solvent, the glycerol, after silanization. The condensation of polysiloxane film is completed on the surface triggering the rupture of intramolecular interactions between silanol and the amino groups.

\subsection{Surface PEGylation of fluorescent silica nanoparticles and characterization}

mPEG5K-ald polymer chains were characterized before grafting step. Despite the mild oxidation conditions used, we first checked if the polymer chains were fragmented. Size exclusion chromatography (SEC) was performed in aqueous medium before and after oxidation of the PEG. The announced molecular weight for commercial PEG was $5000 \mathrm{~g} / \mathrm{mol}$. We found the real $\mathrm{Mw}$ and thus $\mathrm{Mn}$ by combining with refractive index measurements in order to obtain $\mathrm{dn} / \mathrm{dc}$ values: for $\mathrm{mPEG}, \mathrm{Mn}=$ $5600 \mathrm{~g} / \mathrm{mol}$ with a PDI (Mn/Mw) of 1.07 and for $\mathrm{mPEG}$-ald, $\mathrm{Mn}=5700 \mathrm{~g} / \mathrm{mol}$ for a PDI $=1.08$. It can be concluded that the polymer chains are not degraded during this chemical treatment. The slight increasing of the $\mathrm{Mn}$ that is in the error range can be due to the purification steps, for which smallest chains could have been removed. Then, we performed the ${ }^{1} \mathrm{H}-\mathrm{NMR}$ on the PEG after oxidation (The spectrum and comments are shown in supplementary material). The integration of the peaks makes it possible to estimate the yield of the oxidation by taking the signal of the backbone at $3.64 \mathrm{ppm}$ as reference. About $90 \%$ of the mPEG contain an aldehyde termination, so we can consider the yield of the oxidation reaction of about $90 \%$. It can also be noticed the good coherence between the integration of $\mathrm{H} 1$ peaks fixed at 514 and that of $\mathrm{H} 4$ of the methoxy group termination, which gives about 3 protons. The NMR spectrum shows also that about $5 \%$ of mPEG chains are terminated by a methylthiomethylether moiety coming from the reaction with the DMSO, and $5 \%$ others by hydroxyl groups. These fractions do not participate to the grafting reaction and are removed during the washing steps.

DF-SiO ${ }_{2}$ NPs-EDPS were PEGylated by reductive amination between the aldehyde groups of the pre-oxidized mPEG5K molecules and primary amine functions of the NP surface. The TEM micrograph 
of Sample A shows increased spacing between the particles due to the presence of the polymer corona (Fig. 1d). The chemical signature of PEG molecules tethered to aminated silica NPs was evidenced by IR spectroscopy in diffuse reflectance mode on dried particles (Fig. 2) [24]. The strong IR bands at 2940 and $1342 \mathrm{~cm}^{-1}$ were assigned to the asymmetrical and symmetrical (rocking and twisting) stretching modes of the alkyl chains $\left(\mathrm{CH}_{2}\right)$, respectively, while the band at $1465 \mathrm{~cm}^{-1}$ was attributed to deformation vibration $\left(\delta \mathrm{CH}_{2}\right)$. Moreover, the band observed at $2885 \mathrm{~cm}^{-1}$ can be assigned to the asymmetrical or symmetrical (rocking and twisting) stretching modes of the methyl groups $\left(\mathrm{CH}_{3}\right)$. The vibration bands from $400-1200 \mathrm{~cm}^{-1}$ are the signature of Si-O-Si vibrations, mainly with the band at $1100 \mathrm{~cm}^{-1}$ which belongs to antisymmetric stretching vibrations and the bands at 941,801 and $469 \mathrm{~cm}^{-}$

${ }^{1}$ attributed to stretching, bending and rocking vibrations. The shoulder at $1135 \mathrm{~cm}^{-1}$ that appears for highest grafting levels in the middle of this broad band may be attributed to stretching vibrations of C$\mathrm{O}-\mathrm{C}$ ether bonds. It can also be observed that the intensity of the silica bands in the spectra decreases gradually as the amount of PEG increases. All the spectra were performed with the same amount of product so this observation also confirmed by TGA analysis can be really assigned to the enrichment of PEG molecules from Sample D to A.

TGA diagrams (Fig. 3a) of DF-SiO ${ }_{2}$ NPs-PEG5K samples were performed in the same conditions (drying, weighing and thermal cycles) for a better comparison. They show a significant difference of mass losses between each level of PEGylation, from $28 \%$ for Sample D up to $47 \%$ for Sample A. Values of surface grafting density, $\sigma$, are compiled in Table 1 and presented in Fig. 1b. Regarding the evolution of the surface grafting densities as a function of the amount of PEG macromolecules, the saturation conditions are obtained for Sample A, while Sample B has a coverage of $91.5 \%$ relative to Sample A. Note that the reductive amination is quite effective in the chosen conditions since the grafting yield for the Sample D is about $50 \%$ which is quite a high value for a surface grafting reaction. Indeed, it has been showed that the reduction of aldimines with sodium borohydride carried out directly in $\mathrm{MeOH}$ gave the corresponding secondary amines in very high yields and very short reaction times, which makes this method very efficient when applied to substrates [25].

\begin{tabular}{ccccccc}
$\begin{array}{c}\text { Sample } \\
\text { DF-SiO2NPs-PEG }\end{array}$ & $\boldsymbol{N}(\mathbf{E q}$.) & $\begin{array}{c}\boldsymbol{\sigma} \\
\text { (molec./nm } \mathbf{n})\end{array}$ & $\begin{array}{c}\boldsymbol{R}_{\boldsymbol{F}}(\mathbf{P E G}-\mathbf{5 k}) \\
(\mathbf{n m})\end{array}$ & $\boldsymbol{D}(\mathbf{n m})$ & $\boldsymbol{R}_{\boldsymbol{F}} / \boldsymbol{D}$ & $\begin{array}{c}\text { Conformational } \\
\text { regime }\end{array}$ \\
\hline Sample A & 9 & 0.51 & 6.6 & 1.58 & 4.18 & Brush \\
Sample B & 0.9 & 0.47 & 6.6 & 1.65 & 4.00 & Brush \\
Sample C & 0.45 & 0.35 & 6.6 & 1.91 & 3.46 & Brush \\
Sample D & 0.09 & 0.18 & 6.6 & 2.66 & 2.48 & Brush \\
\hline
\end{tabular}

Table 1. Values of surface grafting density obtained by TGA analysis and corresponding conformational regimes. $\mathrm{N}(\mathrm{Eq}$.) is the number of equivalent of PEG used for each synthesis that takes into account the oxidation yield of mPEG (i.e. 90\%). 
The conformational regimes of PEG molecules grafted on the NP surface were calculated from the values of $\sigma$ obtained by TGA. The structural conformation depends on the average distance $D(D=$ $\left.2(\pi \sigma)^{-\frac{1}{2}}\right)$ between neighboring PEG chains [26]. When D is smaller than the Flory radius $\left(R_{F}=a N^{\frac{3}{5}}\right.$, where $a$ is the effective monomer PEG length $=0.358 \mathrm{~nm}$ [27], $N$ the degree of polymerization), adjacent chains overlap and the PEG chain stretch away from the surface forming a brush layer. If $R_{F} / D$ $\leq 1$, neighboring PEG molecules are not overlapped and form the mushroom conformational regime. In the present study, all the PEG layers present a brush conformational regime.

The thickness of the PEG layer was assessed using DLS measurements (table 2). These values are determined by subtracting the hydrodynamic diameter represented by the Z-average size measured in PBS (or water see Supporting material document table S3) from the physical diameter of DF-SiO ${ }_{2} \mathrm{NPs}$ determined by TEM observations $\left(R_{T E M}=9.5 \mathrm{~nm}\right.$ ). As PEG grafting density increases, compression of adjacent PEG molecules increases the hydrodynamic diameter from 45.2 for low $\sigma$ up to $50.3 \mathrm{~nm}$ for the higher value of $\sigma$. The thickness of the PEG layer has been initially predicted by the theoretical work of Alexander [28] and de Gennes [29] in the case of planar brushes. These pioneering works predicted a linear dependence of brush height, $h$, on the degree of polymerization, $N: h=a N \sigma^{* \frac{3}{5}}$ ( $a$ is the monomer length and $\sigma^{*}=\sigma l_{0}^{2}$ is the reduced grafting density [30] and $I_{0}$ the average bond length). Since then, numerous studies have considered the curvature of the surface of nanoparticles to determine the thickness of the PEG layer [30, 31-34]. A generalized treatment for curved brushes was presented by Daoud and Cotton [31], who extended the phenomenological scaling arguments of Alexander and de Gennes to the somewhat related context of star polymers. This theory was extended for grafted polymers on particles by Vagberg et al. [32]. The hydrodynamic thickness $L s$ of the swollen brush layer on a particle of radius $R$ is approached by the following equation:

$$
L_{S}=\left(\frac{8 N_{k} f^{\frac{1-v}{2 v}}}{3 \times 4 \frac{1}{v} v} L_{k}^{\frac{1}{v}}+R^{\frac{1}{v}}\right)^{v}-R
$$

where $N_{k}$ is the statistical number of Kuhn segments $\left(N_{k}=n / c_{\infty}\right.$ with $n$ the number of chemical bonds in the macromolecule i.e. 3 times the degree of polymerization $N$ and the characteristic ratio, $c_{\infty}=$ 4.1 for PEG), $L_{k}$ the Kuhn length ( $L_{k}=c_{\infty} l_{0}$ with $l_{0}$ the average bond length $=0.147 \mathrm{~nm}$ for PEG), $f$ the number of grafted chains ( $f=4 \pi R^{2} \sigma$ ) and $v$, the scaling factor ( $v=3 / 5$ for good solvents). Apart from Sample D, the calculated values of $L s$ listed in Table 2 match quite well with those measured by DLS following the same general trend. 


\begin{tabular}{ccccccc} 
Sample & DTEM(nm) & $\boldsymbol{R f}(\mathbf{n m})$ & $\begin{array}{c}\text { Z-Ave(PBS) } \\
(\mathbf{n m})\end{array}$ & $\boldsymbol{P D I}$ & $\boldsymbol{L s}_{\text {exp }}(\mathbf{n m})$ & $\boldsymbol{L s}_{\text {th }}(\mathbf{n m})$ \\
\hline Sample A & 19 & 6.6 & 50.3 & 0.13 & 15.6 & 13.9 \\
Sample B & 19 & 6.6 & 48.8 & 0.16 & 14.9 & 13.6 \\
Sample C & 19 & 6.6 & 45.1 & 0.10 & 13.0 & 12.6 \\
Sample D & 19 & 6.6 & 45.2 & 0.19 & 13.1 & 10.5 \\
\hline
\end{tabular}

Table 2. Values of hydrodynamic diameters, polydispersity indexes (PDI) and experimental and theoretical thicknesses of PEG layer obtained by Eq.1.

The gap between measured and calculated values of $L s$ is attributed to the slight size polydispersity of NPs that can induce an overestimation of the Z-average due to the more important light scattering of bigger particles. While this model predicts a deviation of $3.4 \mathrm{~nm}$ in thickness of the polymer corona between samples $A$ and $D$, the DLS measurements give a difference of $2.5 \mathrm{~nm}$, which is a good agreement in view of the size dispersion. In mushroom regime where polymer blobs are not in interactions, the thickness $L s$ of the polymer layer would correspond to the Flory radius of the PEG chains. Here, in brush conformational regime, it can be observed the increasing of the thickness layer with $\sigma$, which physically corresponds to the stretching of the polymer chains that compress together when the grafting density increases.

In the aim to avoid the screening of the surface charges, zeta potential measurements were first performed in water that is a medium of low ionic strength (measured conductivity values varying from 0.04 to $0.17 \mathrm{mS} / \mathrm{cm}$ according to the measured sample) (Fig. 4). The zeta potential profile shows that the PEGylated NPs exhibit increasingly near-neutral values as the surface PEG coverage increases. Although values decrease drastically, they still remain positive due to the presence of free inner tethering amine sites and by the fact that primary amine groups are converted to secondary amines during the reaction. The presence of the polymer corona directly impacts the $\zeta$ values by moving the slipping plane away from the NP surface. In PBS, all the inner charges of the NP surface are entirely screened due to the high ionic strength and the PEGylated NPs can be considered as completely neutral.

The presence of the fluorescent dyes trapped inside the nanoparticles after PEGylation was confirmed by spectrophotometry and fluorescence spectroscopy (Fig. 5). The absorbance spectra (Fig. 5a) show the presence of both fluorophores independently of PEG density of each sample. No diffusion overlap is observed due to the small size and the colloidal stability of the dispersion. Fluorescence spectra (Fig. 5b) display the expected values of excitation and emission maxima wavelengths showing that the dyes resisted the various chemical treatments. In these spectra it can be observed a bathochromic shift for the two fluorophores (656/677 and 792/813 nm in silica NPs, against 652/672 and $770 / 794$ for the dyes in water). This red shift may be caused by changes in the environment of dye molecules, such as changes in polarity or polarizability. The silica matrix is not expected to change 
much upon increasing the dye concentration, but the number of dye molecules that are in each other vicinity increases. This leads to interactions between neighboring molecules, which lowers their excited state energy and produces a red shift in the spectra [35].

\subsection{In vivo imaging of the EPR effect of nanoparticles in tumors}

RM1-CMV-Fluc cells were injected subcutaneously on the right leg of mice $(\mathrm{N}=24)$. One week after cell implantation, mice were first assayed for Fluc activity by BLI (Fig. 6). Nanoparticles were then injected via the tail vein and fluorescence distribution of the nanoparticles was monitored with FRI 1, 4, 8, 24 and 48 hours after injection. Mice were separated in 4 experimental batches. The first batch of mice $(N=6)$ was injected with Sample $A$, the second batch $(N=6)$ with Sample B, the third batch ( $N$ =6) with Sample $C$ and the last batch $(N=6)$ with Sample $D$ (Fig. 6).

Representative fluorescence images showed that Sample A quickly accumulated in the tumor as revealed by an increased fluorescence signal $1 \mathrm{~h}$ after injection; whereas for the other NPs with lower levels of PEGylation no fluorescence appeared in the tumor. In contrast, a strong accumulation of Samples B, C and D was detected in the liver just 1 hour after injection. In vivo images showed also that the fluorescence signal resulting from nanoparticle accumulation within the tumor was much stronger for Sample A than the three other NP-batches. Time courses over $48 \mathrm{~h}$ of nanoparticles accumulation in the tumor and liver were represented on the graphs in Fig. 7, and corroborate that the PEGylation level of Sample A permitted a quick and strong accumulation of the nanoparticles in the tumor. The Samples B, C and D largely accumulated in the liver within $1 \mathrm{~h}$ while the liver uptake is drastically slower for the Sample A (Fig. 7a). Interestingly, the fluorescence intensities of the Samples B, C and D gradually decrease (by about $33 \%$ compared to the maximal accumulation values at $1 \mathrm{~h}$ ) within $48 \mathrm{~h}$, probably due to the NP degradation in the liver, in contrast to the trend in the Sample A to increase slowly for $24 \mathrm{~h}(16 \%)$. All the DF-SiO ${ }_{2}$ NPs-PEG5K samples continued to circulate during this period as evidenced by the time course of these NPs towards the tumors (Fig. 7b). The most impressive result here lies in the difference in the EPR effect uptake between Sample A and B which are distinguished by a grafting density difference of only $8.5 \%$. The microscopy image of a tumor slice corresponding to a mouse from Sample A (Fig. 8) shows the fluorescence of DL650 attesting the presence of the NPs all around tumor cells. Even if further characterization has to be performed to determine the precise location of the NPs inside or outside the cells, these dually labelled NPs are obviously good candidates for this type of study at multiple scales using different imaging techniques. 


\section{Discussion}

In the aim of studying the impact of slight variations in the surface grafting density of PEG molecules in the brush regime on the tumor uptake by EPR effect, we chose PEG coatings with $R_{F} / D$ ratio around 2.8. This value represents a threshold corresponding to a dense brush conformational regime beyond which it has been observed an effective stealth behavior of PEGylated $100 \mathrm{~nm}$ polystyrene NPs against human monocytic THP-1 cells in vitro [14]. We preferred also in this study a NP size of around $20 \mathrm{~nm}$ (without the outer PEG layer), too big to be cleared by renal excretion [36] and small enough to decrease the macrophage uptake [13]. We used a single PEG molecular weight typically of $5000 \mathrm{~g} / \mathrm{mol}(\mathrm{Mn} 5700 \mathrm{~g} / \mathrm{mol}, \mathrm{PDI} 1.08$ ) that displays a good ability to decrease protein adsorption onto the NP surfaces [13,37-39]. These PEG molecules were first functionalized by aldehyde groups before grafting on surface chemically modified silica NPs. The chemical surface modification previously optimized on silica nanoparticles [16] allows a control over the grafting rate in order to generate several samples of different $R_{F} / D$ ratios of $2.48,3.46,4.00$ and 4.18 . Light in the visiblewavelength range is routinely used for conventional and intravital microscopy [40] but emission spectra within the near infrared (NIR) window (700-900 nm) must be used for deep in vivo imaging because of absorption and tissue autofluorescence [41]. The dual doping of silica NPs described in the present work enabled their tracking in vivo by FRI by using DL 800 wavelength in the near infra-red (NIR) windows and microscopic imaging in vitro using DL 650. RM1 cells provided rapidly growing tumors in immunocompetent mice including subcutaneous, orthotopic and metastasis [42]. In the present work, subcutaneous tumors were generated at the same time and tumor growth was further followed by individual BLI measurement ensuring homogeneity between the experimental series when mice were injected with NPs. Although FRI did not provide absolute quantification, it allowed the monitoring of NP accumulation in both subcutaneous tumors and in the liver. FRI clearly discriminated NP behavior in vivo according to PEG status.

Despite the fact that all the PEGylated NPs are in the brush conformational regime, they do not suffer the same fate in vivo. A rapid accumulation in the liver was expected for NPs displaying a $\mathrm{R}_{\mathrm{F}} / \mathrm{D}$ under the threshold value of 2.8, but less expected for PEGylated NPs with values of 3.46 and 4.00 . For $R_{F} / D=3.46$ and 4.00 the uptake by the EPR effect increase gradually but remain reduced due to the rapid extravasation by the liver. For $R_{F} / D=4.18$, an increase of fluorescence in tumor as well as in liver was observed for up to $24 \mathrm{~h}$. In this case the intensity of tumor fluorescence approximately corresponds to the fluorescence observed in the liver which means that this level of PEGylation enables an important percentage of these NPs to evade the RES. The most surprising outcome is the huge difference in biodistribution kinetics between Samples A and B whose main difference results from a slight change of PEG coverage, a difference of $8.5 \%$. The NPs used in this study presented a more 
elevated curvature than those used in the previous report of Lai et al.[14] and it seems also possible that the $\mathrm{R}_{\mathrm{F}} / \mathrm{D}$ threshold is shifted from 2.8 to about 4. Indeed, Chan et al. observed on gold nanoparticles of sizes varying from 15 to $90 \mathrm{~nm}$, that under fixed PEG grafting density, decreasing nanoparticles size increases plasma protein absorption [13]. Highly curved surfaces impact the intermolecular PEG-PEG interactions within the polymer corona. The molecules tend to spread out in the volume gained away the convex surface which lowers the thermodynamic barrier to opsonisation and thus, affects the threshold value.

The hydrodynamic diameters of Samples A and B and the PEG volume fractions represent 94 and $93.7 \%$ of the overall NP volume respectively. The saturation of surface was reached by applying a 10fold excess of PEG relative to Sample B in a very concentrated PEG medium (358 g/L, 30 \% v/v) which results in a gain of $8.5 \%$ in terms of surface grafting density. Although monodisperse macromolecules are certainly close together, with such excess, there may be small chains in the environment that can fill vacant spaces between the larger chains without really affecting the thickness values. Furthermore, this slight variation of $8.5 \%$ implies a difference in the structuration of the PEG layer between both NPs, which materializes in the formations of gaps by overlapping neighboring chains, entanglements, and many spatial configurations over very short time intervals [43]. Moreover, the NP environment, that is the blood, is composed of over 3000 different proteins [44] representing an overall concentration of $60 \mathrm{~g} / \mathrm{L}$. These proteins are capable of interacting with the underlying NP surface where free ammonium sites remain. Neighboring proteins can immediately exploit any space formed in the molecular layer leading to opsonisation. This structuration of the PEG layer influences the composition and thickness of the protein corona which have been demonstrated to have a deep impact on the biological fate of PEGylated NPs $[13,14,45,46]$. The structure of the stealth polymer layer can determine the type of plasma protein. Even in some cases, it has been demonstrated that clusterin, a plasma protein named also apolipoprotein J, has been shown to adsorb on PEGylated $100 \mathrm{~nm}$ polymer NPs. This plasma protein can reduce non-specific cellular uptake and assists the stealth effect [47]. Tenzer et al. observed differences in the composition of the protein corona between silica nanoparticles of $8 \mathrm{~nm}, 20 \mathrm{~nm}$ and $125 \mathrm{~nm}$ [48]. Indeed, the curvature radius affects the contact surface between the nanoparticle and the biomolecule, which induces differences in affinity. The curvature radius also affects the level of conformational changes of adsorbed proteins [49].

The results of our experiments suggest that small NPs with highly curved surfaces are much more sensitive to slight variations of PEG surface grafting density with respect to RES clearance. The intermolecular spacing generated by a high radius of curvature must be compensated by high grafting densities through a saturated polymer layer. When their surface grafting density is sufficiently high, dually fluorescent silica nanoparticles have shown their ability to label the EPR effect in mice bearing 
tumors with longer blood circulation times up to 24 hours. Our results underscore the need to thoroughly control the surface chemistry and the PEG grafting density on small nanoparticles to achieve dense brush regimes as a prerequisite to passive tumor targeting and before designing targeting strategies. In this study, the control of the conjugation was achieved by the combination of functionalized nanoparticles offering a large number of accessible functions with an anchoring reaction of high yield in a good PEG solvent. Such PEGylated fluorescent NPs could be valuable labels to detect and assess the magnitude of the tumor EPR effect.

\section{Transparency Document}

The Transparency document associated with this article can be found, in the online version.

\section{Acknowledgement}

We thank Dr. Pierre Costet and Laetitia Medan from Univ. Bordeaux animal's facilities service for the animals' care. The authors are also grateful to Dr Olivier Sandre and Amélie Vax of the Laboratory of Organic Polymer Chemistry (LCPO) for DLS, SEC measurements, and fruitful discussions; to Dominique Denux and Philippe Dagault of the Bordeaux's Institute of Condensed matter Chemistry (ICMCB) for TG analysis and to Dr. Claire Mazzocco (EA IMOTION) for cell line engineering. Laurent Adumeau was a recipient of a scholarship from the French Ministry of Education and Research. This work was supported by Labex TRAIL (ANR-10-LABX-57).

\section{References}

[1] W. R. Sanhai, J. H. Sakamoto, R. Canady, M. Ferrari, Seven challenges for nanomédecine, Nat. Nanotech. 3 (2008) 242-244.

[2] N. Bertrand, J. Wu, X. Xu, N. Kamaly, O. C. Farokhzad, Cancer nanotechnology: The impact of passive and active targeting in the era of modern cancer biology, Adv. Drug Deliv. Rev. 66 (2014) 2-25.

[3] L. Brannon-Peppas, J. O. Blanchette, Nanoparticles and targeted systems for cancer therapy, Adv. Drug Deliv. Rev. 56 (2004) 1649-1659.

[4] X.-Q. Zhang, X. Xu, N. Bertrand, E. Pridgen, A. Swami, O.C. Farokhzad, Interactions of nanomaterials and biological systems: implications to personalized nanomedicine, Adv. Drug Deliv. Rev. 64 (2012) 1363-1384.

[5] P. Opanasopit, M. Nishikawa, M. Hashida, Factors affecting drug and gene delivery: Effects of interaction with blood components, Crit. Rev. Ther. Drug Carrier Syst. 19 (2002) 191-233.

[6] S.D. Li, L. Huang, Pharmacokinetics and Biodistribution of Nanoparticles, Mol. Pharmaceutics, 5 (2008) 496-504.

[7] S. Nie, Understanding and Overcoming Major Barriers in Cancer Nanomedecine, Nanomedecine 5 (2010) 523-528 
[8] R. Gref, A. Domb, P. Quellec, T. Blunk, R.H. Muller, J.M. Verbavatz, R. Langer, The controlled intravenous delivery of drugs using PEG-coated sterically stabilized nanospheres, Adv. Drug Deliv. Rev. 16 (1995) 215-233.

[9] A. Vonarbourg, C. Passirani, P. Saulnier, J.P. Benoit, Parameters influencing the stealthiness of colloidal drug delivery systems, Biomaterials 27 (2006) 4356-4373.

[10] F. Alexis, E. Pridgen, L.K.Molnar, O.C. Farokhzad, Factors affecting the clearance and biodistribution of polymeric nanoparticles, Mol. Pharm. 5 (2008) 505-515.

[11] J.V. Jokerst, T. Lobovkina, R.N. Zare, S.S. Gambhir, Nanoparticle PEGylation for imaging and therapy, Nanomedicine (Lond) 6 (2011) 715-728.

[12] J. L. Suk, Q. Xu, N. Kim, J. Hanes, L. M. Ensign, PEGylation as a strategy for improving nanoparticlebased drug and gene delivery, Adv. Drug. Deliv.Rev. 99 (2016) 28-51.

[13] C. D. Walkey, J. B. Olsen, H. Guo, A. Emili, W. C. W. Chan, Nanoparticle Size and Surface Chemistry Determine Serum Protein Adsorption and Macrophage Uptake, J. Am. Chem. Soc. 134 (2012) 21392147.

[14] Q. Yang, S. W. Jones, C. L. Parker, W. C. Zamboni, J. E. Bear, S. K. Lai, Evading Immune Cell Uptake and Clearance Requires PEG Grafting at Densities Substantially Exceeding the Minimum for Brush Conformation, Mol. Pharmaceutics 11 (2014) 1250-1258.

[15] S. Mornet, J. Portier, E. Duguet, A method for synthesis and functionalization of ultrasmall superparamagnetic covalent carriers based on maghemite and dextran, J. Magn. Magn. Mater. 293 (2005) 127-134.

[16] N. Reinhardt, L. Adumeau, O. Lambert, S. Ravaine, S. Mornet, Quaternary Ammonium Groups Exposed at the Surface of Silica Nanoparticles Suitable for DNA Complexation in the Presence of Cationic Lipids, J. Phys. Chem. B 119 (2015) 6401-6411.

[17] K. E. Pfitzner, J. G. Moffatt, A New and Selective Oxidation of Alcohols, J. Am. Chem. Soc., 85 (1963) 3027-3028.

[18] G. Tojo, M. Fernandez, Oxidation of Alcohols to Aldehydes and Ketones, a guide of common practice, Book chapter, 97-179, G. Tojo Ed., Springer Science and Business Media, Inc., New York, 2006.

[19] Park, P.-U.; Kim, S.-N.; Choi, W.-H.; Jang, H.-S.; Lee, G.-S.; Kwon, S.-C. Method for preparing highpurity polyethyleneglycol aldehyde derivatives, US8349969 B2, January 8, 2013.

[20] C. Mazzocco, G. Fracasso, C. Germain-Genevois, N. Dugot-Senant, M. Figini, M. Colombatti, N. Grenier, F. Couillaud, In vivo imaging of prostate cancer using an anti-PSMA scFv fragment as a probe, Sci. Report. 6 (2016) 23314.

[21] W. Stöber, A. Fink, E. Bohn, Controlled growth of monodisperse silica spheres in the micron size range, J. Colloid Interface Sci. 26 (1968) 62-69.

[22] A. V. Blaaderen, A. Vrij, Synthesis and Characterization of Colloidal Dispersions of Fluorescent, Monodisperse Silica Spheres, Langmuir 8 (1992) 2921-2931.

[23] D. R. Larson, H. Ow, H. D. Vishwasrao, A. A. Heikal, U. Wiesner, W. W. Webb, Silica Nanoparticle Architecture Determines Radiative Properties of Encapsulated Fluorophores, Chem. Mater. 20 (2008) 2677-2684 
[24] R. M. Silverstein, F. X. Webster, D. J. Kiemle, Spectrometric identification of organic compounds, 7th ed.; John Wiley \& sons: New York, NY, 2005.

[25] A. F. Abdel-Magid, K. G. Carson, B. D. Harris, C. A. Maryanoff, R. D. Shah, Reductive Amination of Aldehydes and Ketones with Sodium Triacetoxyborohydride. Studies on Direct and Indirect Reductive Amination Procedures, J. Org. Chem. 61 (1996) 3849-3862.

[26] P. G. De Gennes, Polymers at an interface; a simplified view, Adv. Colloid Interface Sci. 27 (1987) 189-209.

[27] M. A. Rixman, D. Dean, C. Ortiz, Nanoscale Intermolecular Interactions between Human Serum Albumin and Low Grafting Density Surfaces of Poly(ethylene oxide), Langmuir 19 (2003) 9357-9372.

[28] S. Alexander, Adsorption of chain molecules with a polar head a scaling description, J. Phys. France 38 (1977) 983-987.

[29] P. G. de Gennes, Conformations of Polymers Attached to an Interface, Macromolecules 13 (1980) 1069-1075

[30] D. Dukes, Y. Li, S. Lewis, B. Benicewicz, L. Schadler, S. K. Kumar, Conformational Transitions of Spherical Polymer Brushes: Synthesis, Characterization, and Theory, Macromolecules 43 (2010) 15641570.

[31] M. Daoud, J. P. Cotton, Star shaped polymers: a model for the conformation and its concentration dependence, J. Phys. France 43 (1982), 531-538.

[32] L. J. M. Vagberg, K. A. Cogan, A. P. Gast, Light-Scattering Study of Starlike Polymeric Micelles, Macromolecules 24 (1991), 1670-1677.

[33] K. Ohno, T. Morinaga, S. Takeno, Y. Tsujii, T. Fukuda, Suspensions of Silica Particles Grafted with Concentrated Polymer Brush: Effects of Graft Chain Length on Brush Layer Thickness and Colloidal Crystallization, Macromolecules 40 (2007) 9143-9150.

[34] E. M. Sevick, Shear Swelling of Polymer Brushes Grafted onto Convex and Concave Surfaces, Macromolecules 29 (1996) 6952-6958.

[35] A. Imhof, M. Megens, J. J. Engelberts, D. T. N. de Lang, R. Sprik, and W. L. Vos, Spectroscopy of Fluorescein (FITC) Dyed Colloidal Silica Spheres, J. Phys. Chem. B, 103 (1999) 1408-1415.

[36] H.S. Choi, W. Liu, P. Mistra, E. Tanaka, J. P. Zimmer, B. Itty Ipe, G. M. Bawendi, J. V. Frangioni, Renal clearance of quantum dots, Nat. Biotechnol. 25 (2007) 1165-1170.

[37] R. Gref, M. Luck, P. Quellec, M. Marchand, E. Dellacherie, S. Harnisch, T. Blunk, R.H. Muller, 'Stealth' corona-core nanoparticles surface modified by polyethylene glycol (PEG): influences of the corona (PEG chain length and surface density) and of the core composition on phagocytic uptake and plasma protein adsorption, Colloids Surf. B: Biointerfaces 18 (2000) 301-313.

[38] A.Mori, A.L. Klibanov, V.P. Torchilin, L. Huang, Influence of the steric barrier activity of amphipathic poly(ethyleneglycol) and ganglioside GM1 on the circulation time of liposomes and on the target binding of immunoliposomes in vivo, FEBS Lett. 284 (1991) 263-266.

[39] Q. Dai, C. Walkey, W.C.W. Chan, Polyethylene Glycol Backfilling Mitigates the Negative Impact of the Protein Corona on Nanopaticle Cell Targeting, Angew. Chem. Int. Ed. 53 (2014) 5093-5096. 
[40] E. B. Brown, R. B. Campbell, Y. Tsuzuki, L. Xu, P. Carmeliet, D. Fukumura, R. K. Jain, In vivo measurement of gene expression, angiogenesis and physiological function in tumors using multiphoton laser scanning microscopy, Nat. Med. 7 (2001) 864-868.

[41] R. Weissleder, V. Ntziachristos, Shedding light onto live molecular targets, Nat Med. 9 (2003) 123128.

[42] C.A. Power, H. Pwint, J. Chan, J. Cho, Y. Yu, W. Walsh, P. J. Russell, A novel model of bonemetastatic prostate cancer in immunocompetent mice, Prostate 69 (2009) 1613-1623.

[43] C. Jeppesen, J. Y. Wong, T. L. Kuhl, J. N. Israelachvili, N. Mullah, S. Zalipsky, C. M. Marques, Impact of polymer tether length on multiple ligand-receptor bond formation. Science 293, 465-468 (2001).

[44] N. L. Anderson, N. G. Anderson, The human plasma proteome: history, character, and diagnostic prospects, Mol. Cell Proteomics. 1 (2002) 845-67.

[45] C. Sacchetti, K. Motamedchaboki, A. Magrini, G. Palmieri, M. Mattei, G. Bernardini, N. Rosato, N. Bottini, M. Bottini, Surface PEG Conformation Influences the Protein Corona of Polyethylene GlycolModified Single-Walled Carbon Nanotubes: Potential Implications on Biological Performance, ACS Nano 7 (2013) 1974-1989.

[46] S. Tenzer, D. Docter, J. Kuharev, A. Musyanovych, V. Fetz, R. Hecht, F. Schlenk, D. Fischer, K. Kiouptsi, C. Reinhardt, K. Landfester, H. Schild, M. Maskos, S. K. Knauer, R. H. Stauber, Rapid Formation of Plasma Protein Corona Critically Affects Nanoparticle Pathophysiology, Nat. Nanotechnol. 8 (2013) 772-781.

[47] S. Schöttler, G. Becker, S. Winzen, T. Steinbach, K. Mohr, K. Landfester, V. Mailänder, F. R. Wurm, Protein adsorption is required for stealth effect of poly(ethylene glycol)- and poly(phosphoester)coated nanocarriers, Nat. Nanotechnol. 11 (2016) 372-377.

[48] S. Tenzer, D. Docter, S. Rosfa, A. Wlodarski, J. Kuharev, A. Rekik, S. K. Knauer, C. Bantz, T. Nawroth, C. Bier, J. Sirirattanapan, W. Mann, L. Treuel, R. Zellner, M. Maskos, H. Schild, R. H. Stauber, Nanoparticle Size Is a Critical Physicochemical Determinant of the Human Blood Plasma Corona: A Comprehensive Quantitative Proteomic Analysis, ACS Nano 5 (2011) 7155-7167.

[49] C. D.Walkey, W. C. W Chan, Understanding and controlling the interaction of nanomaterials with proteins in a physiological environment, Chem. Soc. Rev. 41 (2012) 2780-2799. 


\section{Figures and captions}

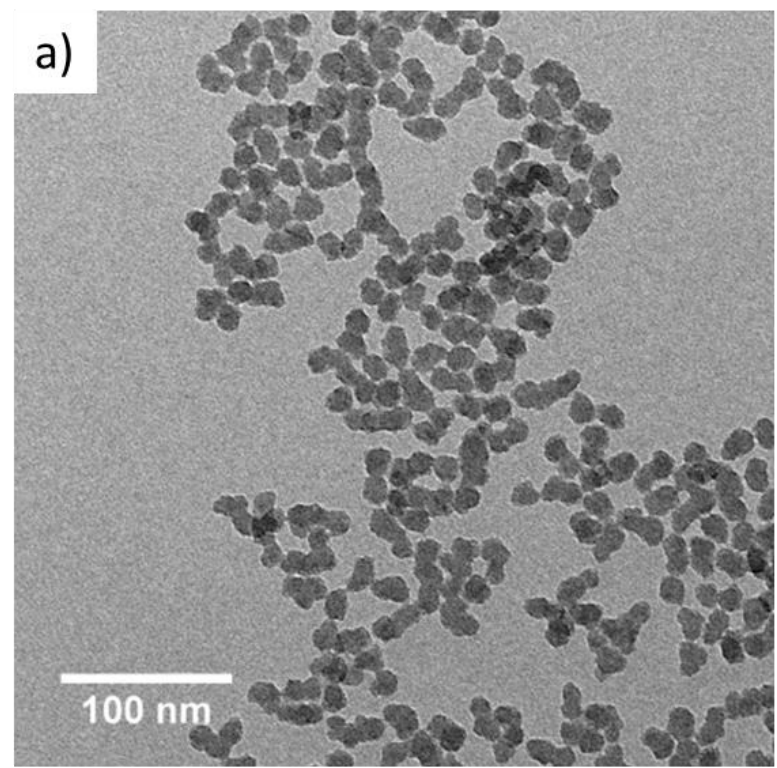

b)

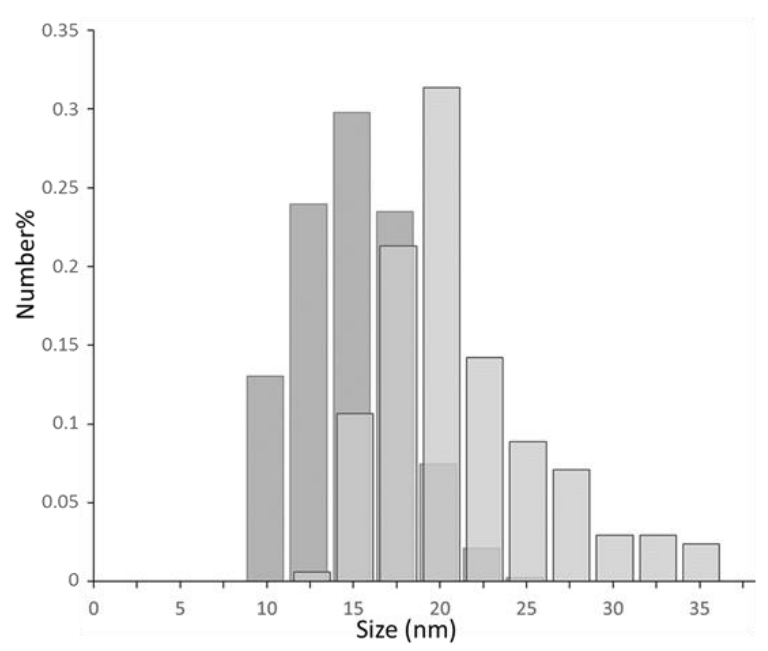

c)

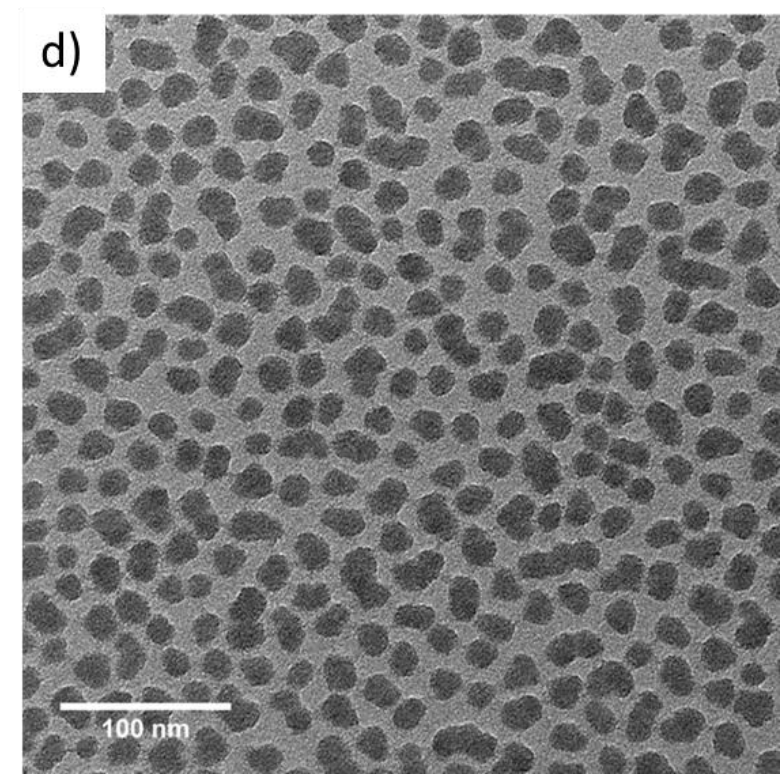

Fig. 1 TEM micrographs of a) $15 \mathrm{~nm}$ sized fluorescent silica cores, c) after growing with $2 \mathrm{~nm}$ thick silica

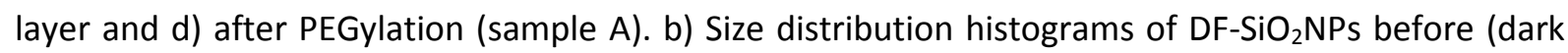
grey) and after (light grey) the silica growing. 


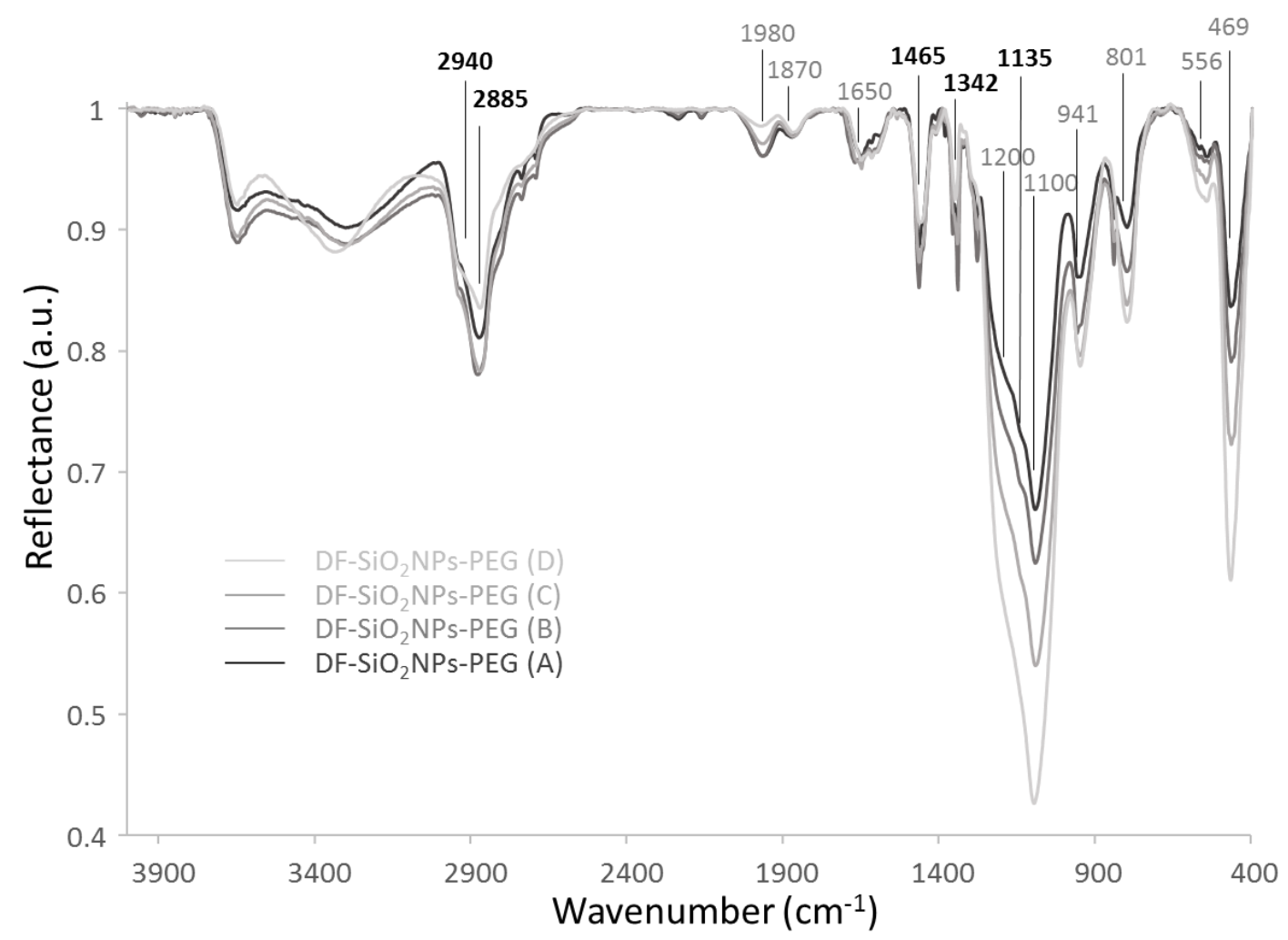

Fig. 2 Infrared spectra of PEGylated silica NPs with increasing grafting densities.

a)

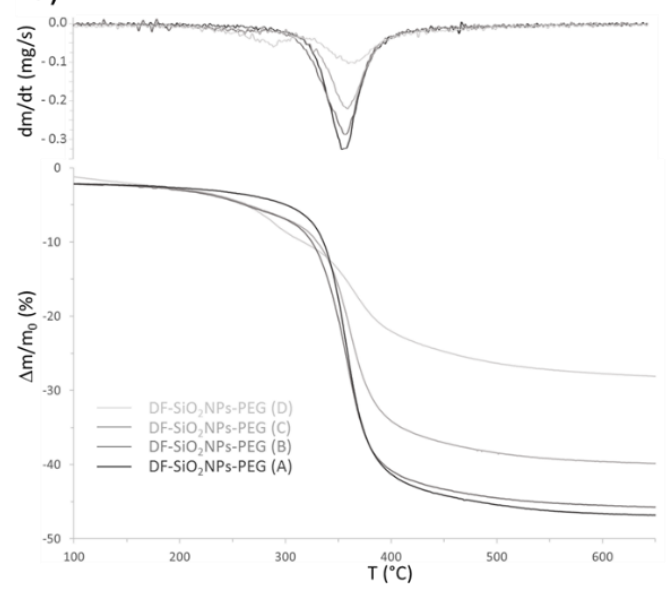

b)

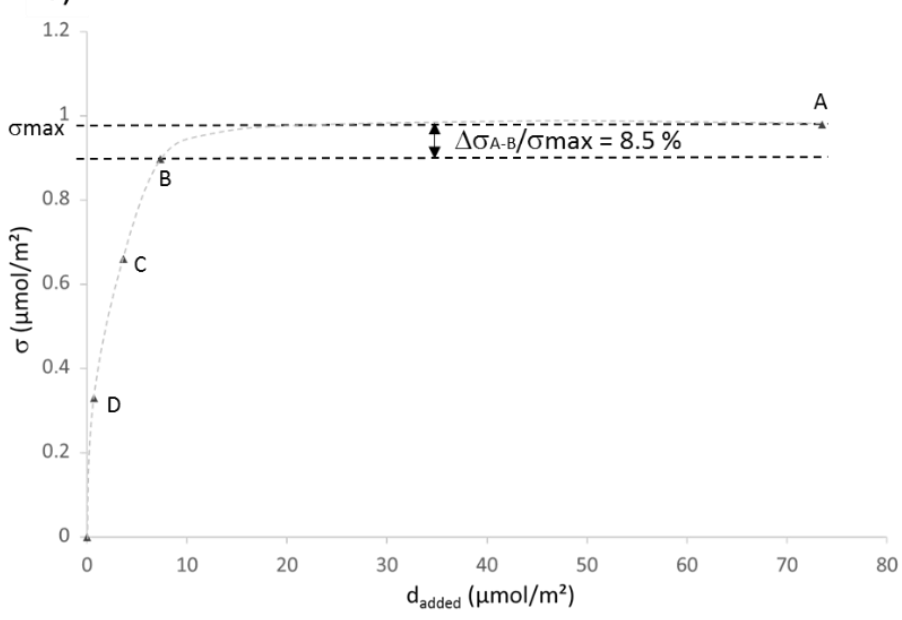

Fig. 3 a) down, TGA diagrams showing the percentual mass loss of silica nanoparticles resulting from different levels of PEGylation; up, differentiated TGA diagrams of DF-SiO ${ }_{2}$ NPs-PEG samples. b) Calculated surface grafting densities of PEG molecules (expressed in $\mu \mathrm{mol} / \mathrm{m}^{2}$ ) from TGA assessments in function of the amount of PEG added per surface unit ( $d_{\text {added }}$ ). The dashed line is just a guide for the eye. 


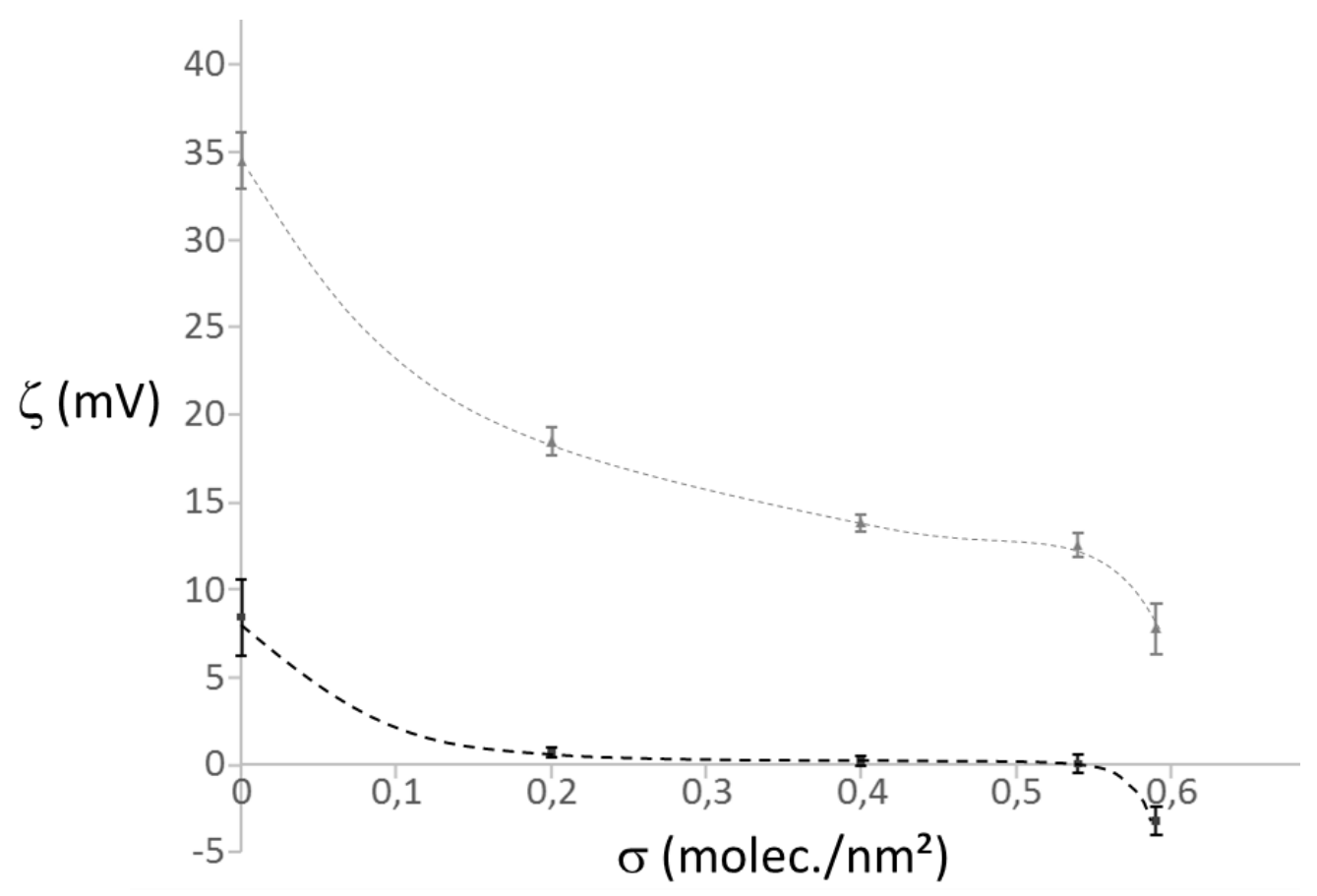

Fig. 4 Zeta potential profiles of PEGylted silica NPs in water (light grey) and PBS buffer (dark grey) vs increasing surface grafting densities of PEG molecules. The dashed lines are just guides for the eye.
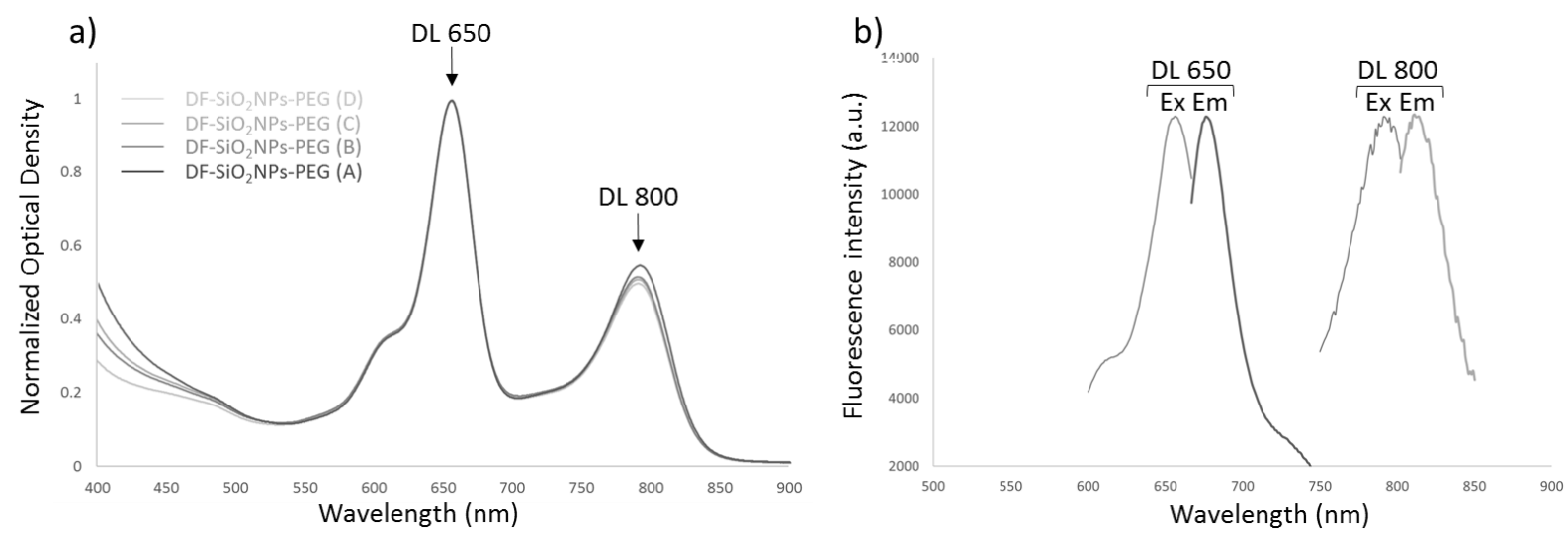

Fig. 5 a) Absorbance spectra of dually fluorescent silica nanoparticles after PEGylation. b) fluorescence spectre of DF-SiO 2 NPs-PEG (A) sample ( $\lambda_{E X} / \lambda_{E M} 656 / 677 \mathrm{~nm}$ and $\lambda_{E X} / \lambda_{E M} 792 / 813 \mathrm{~nm}$ ). 
$\mathrm{BLI}$

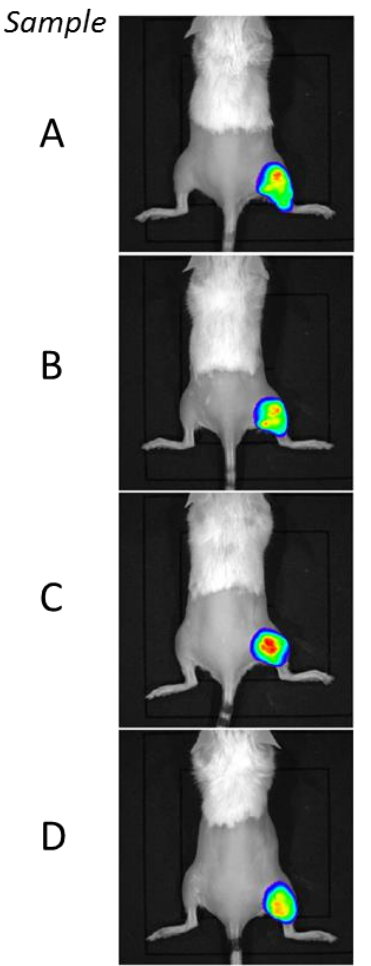

$1 \mathrm{~h}$
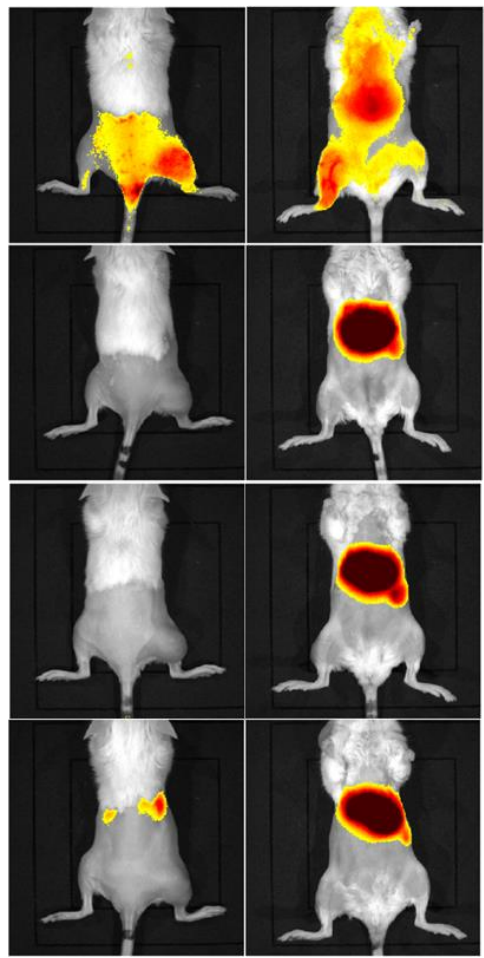

$8 \mathrm{~h}$
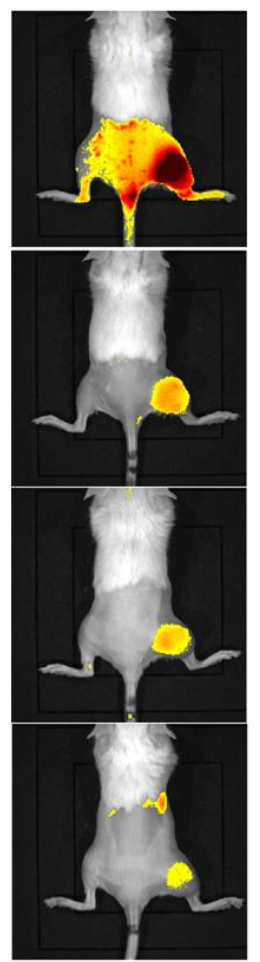

$48 \mathrm{~h}$

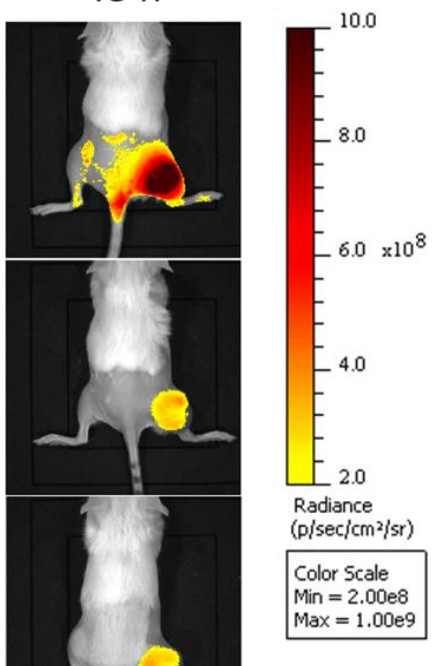

Fig. $6 \mathrm{BLI}$ (prone position) and FRI of a representative mouse from batch $\mathrm{A}$, batch $\mathrm{B}$, batch $\mathrm{C}$ and batch D injected with corresponding DF-SiO ${ }_{2}$ NPs-PEG5k (samples A, B, C and D) observed at $1 \mathrm{~h}$ (right, prone position; left, supine position), $8 \mathrm{~h}$ and $48 \mathrm{~h}$ (prone position).
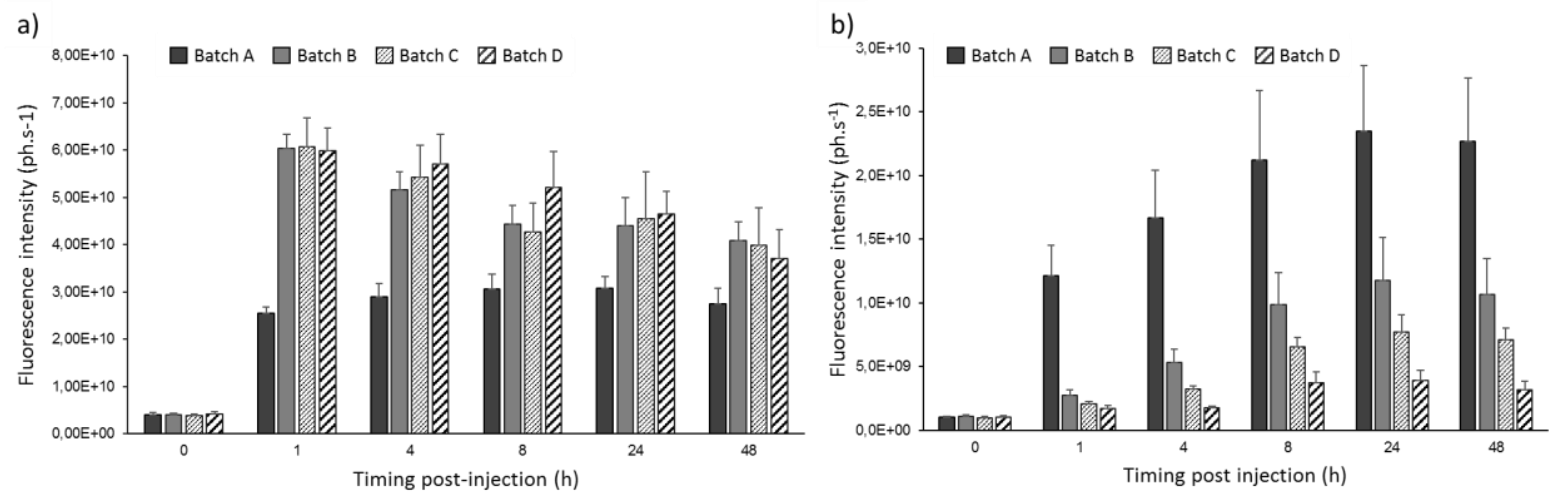

Fig. 7 Time courses of DF-SiO ${ }_{2}$ NPs-PEG5k (samples A, B, C and D) accumulation: $a$ ) into the liver, b) into the tumors of mice bearing RM1 subcutaneous tumors ( $\mathrm{N}=6$ for each batch). 


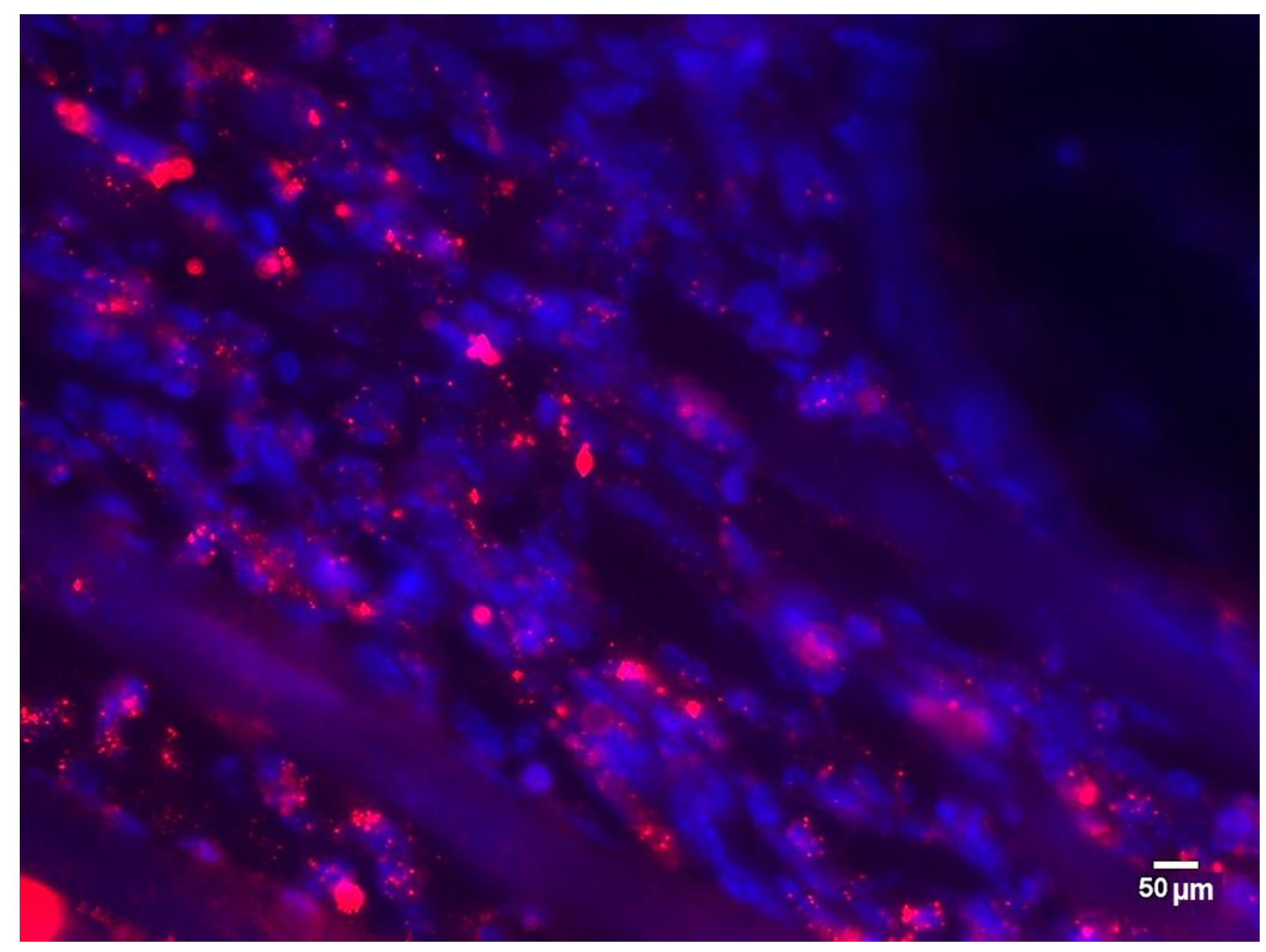

Fig. 8 Microscopy image of a tumor slice from a mouse injected 48 hours after with sample A. Blue staining (DAPI) evidences nuclei cells while red color is due to the fluorescence of DL650 of the NP. 